\section{EMBRYRIDDLE}

Aeronautical University

SCHOLARLY COMMONS
Journal of Aviation/Aerospace

Education \& Research

Volume 1

Number 2 JAAER Fall 1990

Article 14

Fall 1990

\title{
Pilot's Evaluation of the Usefulness of Full Mission IFR Simulator Flights for General Aviation Pilot Training
}

Leonard E. Ross Ph.D.

Paul W. Slotten

Louise M. Yeazel Ph.D.

Follow this and additional works at: https://commons.erau.edu/jaaer

\section{Scholarly Commons Citation}

Ross, L. E., Slotten, P. W., \& Yeazel, L. M. (1990). Pilot's Evaluation of the Usefulness of Full Mission IFR Simulator Flights for General Aviation Pilot Training. Journal of Aviation/Aerospace Education \& Research, 1(2). https://doi.org/10.15394/jaaer.1990.1024

This Article is brought to you for free and open access by the Journals at Scholarly Commons. It has been accepted for inclusion in Journal of Aviation/Aerospace Education \& Research by an authorized administrator of Scholarly Commons. For more information, please contact commons@erau.edu. 


\title{
PILOTS' EVALUATION OF THE USEFULNESS OF FULL MISSION IFR
}

\section{SIMULATOR FLIGHTS FOR GENERAL AVIATION PILOT TRAINING}

\author{
Leonard E. Ross, Ph.D., Paul W. Slotten,
}

and Louise M. Yeazel, Ph.D.

\section{ABSTRACT}

Professional pilots, including flight instructors, who had participated in multiple session line-oriented flight training (LOFT) Instrument Flight Rules (IFR) simulator flights differing in task difficulty evaluated the value of such flights for the training of general aviation pilots. These flights, which employed a relatively low cost simulator (Frasca 141), were judged to be quite useful for instrument student flight training, for instrument rated pilots with moderate instrument experience, and for experienced pilots. The aspects of flight that were seen as receiving the greatest benefit from the flight scenarios were practicing responses to problem situations, attitude instrument flying, practicing instrument approaches under varying weather conditions, and navigation and communications for student pilots. In contrast, the simulator was not seen as useful for Visual Flight Rules (VFR) recurrent training.

\section{INTRODUCTION}

In air transport operations, an increased emphasis has been placed on LOFT in which full mission scenarios are flown in simulators with realistic work loads and simulated emergencies. A major focus of such training has been the functioning of the crew as an operating unit during full missions that often include unexpected flight situations (Helmreich et al., 1990).

In contrast, simulator use in general aviation pilot training is typically focused on the training and assessment of individual pilot skills on more or less discrete and standardized flight tasks, e.g. instrument procedures and skills. This type of simulator-based training usually involves relatively inexpensive simulators, which may or may not have interactive visual displays and motion capability. The question addressed in this study was the degree to which fullmission scenarios flown on training simulators would be assessed by professional pilots, including certificated flight instructors (CFIs), to be of benefit to pilots at a variety of skill levels. The positive features of such training have 


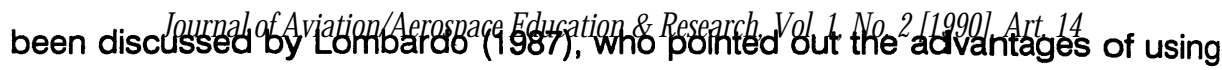
relatively inexpensive simulators and LOFT type scenarios in training and in assessing the pilot's overall ability to plan and execute a full range of flight task operations.

In the present study professional pilots who had participated in a multiple session study involving LOFT-type IFR simulator flights that included a variety of difficult flight situations were asked to evaluate the value of such flights for the flight training of general aviation pilots.

\section{METHOD}

\section{Subjects}

Twenty-two male pilots with no previous training in the Frasca simulator participated in the study. All were instrument rated and current. Seventeen were currently flying for compensation as CFls (10), charter pilots (5), or airline pilots (2). The other five used their IFR ratings for personal or business flying. Ages ranged from 21 to 61 , with a mean and median of 38.8 and 34 , respectively. Total time ranged from a commercially rated pilot with 262 hours to an Airline Transport Pilot (ATP) rated CFI with 8,900 hours. The mean and median hours were 2100 and 900 , respectively.

\section{Apparatus}

The simulator used was a Frasca 141 that had been modified for the LOFT flights by the addition of carburetor temperature and Exhaust Gas Temperature (EGT) gauges, with the former under experimenter control and the latter realistically responsive to the simulator's mixture-control settings. A vacuum gauge and backup system switch were also added. An IRIS-2400 based visual system permitted air traffic to be shown and visibility conditions to be controlled in degrees from haze to IMC. The visual graphics were projected by an Electrohome 2400 projector on a screen 1.9 meters wide by 1.4 meters high located 2 meters in front of the pilot. The graphics and navigational aids represented the San Francisco Bay area and included airports with varied runway lengths, some with Visual Approach Slope Indicators (VASIs).

\section{Procedure}

The pilots were given two training sessions of about one hour each. The first consisted of cockpit familiarization, instruction in the use of the King radios https://commons.erau.edu/jaaer/vol1/iss2/14 


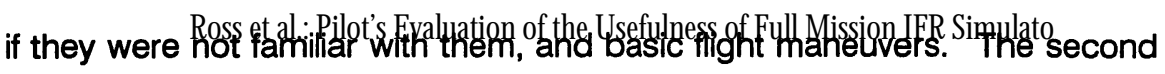
involved precision and non-precision instrument approaches similar to those they would be flying. Following this training, the pilots flew four simulated IFR flights, two on each of two days. The four flights were designed to impose different workload levels on the pilots by varying the complexity and danger of the problem situations encountered. The flights consisted of a base flight in which no problems were introduced and three other flights intended to impose a low, a medium, or a high workload on the pilot. Each subject received a different order of flights with the order across subjects balanced so that each type of flight was given an equal number of times in each order position. Each flight lasted 30-40 minutes, during which an experimenter acted as a controller. Any assistance that would normally have been provided by Air Traffic Control (ATC) was available to the pilot upon request.

To make the flights as realistic as possible, participants were provided with a completed flight plan form, area and en route charts, approach charts for airports in the San Francisco Bay area (NOS or Jeppeson, whichever the subject preferred), and a printout of current and forecast weather. Current Automatic Terminal Information Service (ATIS) information was available en route. After a period to review weather reports, the flight began with an IFR clearance followed by a takeoff in visual conditions and a gradual entry into the clouds at the altitude at which the ceiling was reported. Each flight ended with vectors to an instrument approach course followed by the removal of the clouds at an appropriate point so that the approach could be completed.

The base flight was designed to be an uneventful short IFR flight ending in a normal Instrument Landing System (ILS) approach. The pilot was cleared as filed from Hayward to San Jose, departed RWY 28L at Hayward, entered the clouds at 700 feet, was vectored to the ILS $30 \mathrm{~L}$ final approach course at San Jose, and broke out at 700 feet.

Two changes were introduced for the low workload flight. Moderate turbulence was added, and the pilot was required to make an en route decision between an Non-Directional Beacon (NDB) approach with the ceiling reported at minimums and a Very high Omni Directional Range (VOR) approach to another runway with an 8-knot quartering tail wind. The turbulence that the 


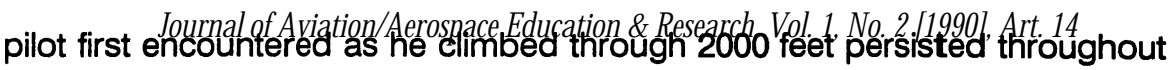
the en route portion of the flight. Approximately 10 minutes from San Jose, he received the current ATIS information indicating that the localizers were out of service, the ceiling was 600 overcast, the wind was 280 degrees at 8 knots, and the only approaches available were the VOR 12 or the NDB/DME 30L. The VOR 12 had an Minimum Descent Altitude (MDA) below the reported ceiling (480 ft.) but a tail wind. The MDA for the NDB/DME 30L (660 ft.) was above the reported ceiling. The rest of the scenario allowed either approach to be completed successfully.

On the medium workload flight, the directional gyro failed during the turn to final on an NDB approach, and the ceiling dropped below minimums, forcing the pilot to fly the missed approach and decide on the next course of action, which could include repeating the NDB approach, attempting a different approach, or asking for a radar assisted "no-gyro" approach.

On the high workload flight, a rapid accumulation of structural ice (simulated by reduction of power to $60 \%$ over a two minute period) was followed by vacuum pump failure in Instrument Meteorlogical Conditions (IMC). The subject was then flying partial panel and gradually losing altitude, with no better weather within range. With expert technique and an immediate decision about a destination, it was possible to land safely on an airport.

Following their participation in the study, subjects were sent a questionnaire soliciting their opinions of the value of this type of flight experience for pilot training. The questions were organized into three sets. The first set of three questions concerned the usefulness of the type of flights experienced for instrument students, for instrument-rated pilots, and for experienced professional pilots. The second set of questions concerned various aspects of flight training that might or might not benefit from this type of simulator training, while the third set of questions was concerned with evaluating particular aspects of the flight experience.

Items included in the questionnaire are presented in Table 1. For each question the subject was asked to place an $\mathrm{x}$ or other mark on a horizontal scale that was five inches long with tic-marks at equal intervals numbered 0 to 10. 


\section{Questions and Mean Scale Values}

Scale values ranged from 0 to 10 with 10 indicating Extremely Useful for question sets 1 and 2, and Quite Similar, Quite Important, and Quite Beneficial for questions 3a, 3b, $3 c$, and $3 d$, respectively.

\section{Non- $>3000<3000$ \\ All CFIs CFIs Hours Hours}

1) Do you feel that simulator flights such as you experienced are useful for training and proficiency?

$\begin{array}{lllll}n=21 & 10 & 11 & 8 & 13\end{array}$

a) For instrument flight training?

$\begin{array}{lllll}8.15 & 8.83 & 7.59 & 8.43 & 8.00\end{array}$

b) For instrument rated pilots with moderate instrument experience?

$\begin{array}{lllll}8.15 & 8.83 & 7.59 & 8.43 & 8.00\end{array}$

c) For experienced professional pilots?

$\begin{array}{lllll}7.53 & 8.00 & 7.10 & 7.14 & 7.75\end{array}$

2) Below are aspects of flight that might or might not benefit from training in a simulator with visuals such as the one you flew. How useful do you think this type of simulator would be for each of the following:

a) Basic flight control for student pilots in VFR and IFR conditions?

$\begin{array}{lllll}5.94 & 6.44 & 5.52 & 6.93 & 5.40\end{array}$

b) Navigation and communication for student pilots?

$\begin{array}{lllll}7.48 & 6.72 & 8.09 & 7.57 & 7.42\end{array}$

c) VFR recurrent training?

$\begin{array}{lllll}2.40 & 2.00 & 2.73 & 2.50 & 2.35\end{array}$

d) Attitude instrument flying?

$\begin{array}{lllll}7.78 & 8.22 & 7.41 & 8.43 & 7.42\end{array}$

e) Practicing instrument approaches under varying weather conditions?

$\begin{array}{lllll}7.58 & 6.94 & 8.09 & 6.57 & 8.12\end{array}$

f) Practicing responses to problem situations such as you encountered?

$\begin{array}{lllll}8.42 & 8.94 & 8.00 & 8.71 & 8.77\end{array}$




\section{All CFls CFls Hours Hours}

3) The questions below are concerned with specific aspects of the simulator and simulator procedures.

a) How similar were the responses you made in the simulator to those you would have made in an actual airplane?

b) How important were the simulator's visuals to its overall effectiveness?

$\begin{array}{lllll}4.60 & 4.72 & 4.50 & 3.86 & 5.00\end{array}$

c) How valuable an experience was flying a complete crosscountry flight compared to what it would have been just flying the segments where problems occurred?

$\begin{array}{lllll}6.50 & 6.19 & 6.73 & 6.00 & 6.73\end{array}$

d) Many flights schools use ground training without interactive visuals for instrument flight training. Would the addition of visuals be of any benefit for instrument students?

\section{RESULTS}

Twenty-one of the twenty-two participants returned the questionnaire. Scale markings were scored to the nearest one-half integer value and means computed for each question. Table 1 presents these mean values for all subjects, for CFls versus non-CFls, and for those with more than and less than 3000 hours total pilot-in-command time. As can be seen, the mean values were quite positive, with the exception of items $2 c$ and $3 b$.

A separate analysis of variance was carried out for the responses to each set of questions. The questions were a repeated measure in each analysis with 
CFI versus non-CFI (CFI factor) and greater than 3000 hours versus less than 3000 hours (Hours factor) as between subjects factors.

The mean values for the three questions in the first set did not differ significantly, $\underline{E}(2,32)=1.92, \underline{p}>.10$, nor were the CFI or Hours factors or any interactions significant, all $\mathrm{p}$ values $>.10$. The mean responses to six questions of the second set were significantly different, $\underline{E}(5,85)=29.81$, $\underline{p}<$ .001 , as might be expected given their different content and the inclusion of the item concerning the usefulness of the simulator for VFR recurrent training. Subsequent $\underline{t}$ tests showed the mean rating for question $2 \mathrm{C}$ to be significantly less than mean ratings of all other questions in this set, and the mean rating for question 2a to be significantly less than all other questions except $2 \mathrm{C}$ (all ps < .05). As with the first set of questions, neither the CFI or Hours factors or their interactions approached significance (all ps $>.10$ ). The four questions in the third set did not differ significantly, $\mathrm{F}(3,45)=1.97, \underline{p}>.10$, nor did the CFI or hours factor, or any interactions reach the .10 level of significance.

Given that the scale values ranged from 0 (not useful) to 10 (extremely useful), it might be assumed that the scale midpoint would reflect an evaluation of moderate usefulness, or perhaps a usefulness judgment without great enthusiasm. It then might be assumed further that mean judgments significantly greater than the 5 midpoint would reflect, or be defined as indicating, a very positive rating of the usefulness of the simulator flights for training or for maintaining proficiency. Accordingly, a t-test was performed on the data for each question comparing its mean rating to the midpoint value of five. Under these assumptions the mean responses to all questions except $2 a$, $3 b$, and $3 d$ showed very positive ratings, with $2 c$, usefulness for VFR concurrent training, significantly below the 5 midpoint (all ps $<.05 /$. Question 3d regarding the value of interactive visuals approached but did not reach significance $(\underline{p}=$ .0549).

\section{DISCUSSION}

Clearly the simulator flights experienced by the pilot participants were evaluated as having considerable usefulness for training and for maintaining pilot proficiency. For the three questions of Question Set 1 that dealt with the overall question of usefulness, the lowest rating given by pilots was a four on 
the scale that ranged from a zero, not useful, to 10, extremely useful. In fact, the mean ratings on all three questions were significantly above the scale midpoint.

The mean response to the question concerning the usefulness of such flights for experienced professional pilots was lower than those evaluating the usefulness for instrument students or instrument rated pilots with moderate instrument experience. While this difference was not statistically significant, it is interesting that those without CFI ratings and high-time pilots rated this question lower than CFls or low-time pilots. Several pilots commented on the questionnaire that the experience was not as useful for high-time pilots, and usually accompanied their remarks with statements about the value of simulator realism, with an occasional comment that the simulator did not "feel" like a real airplane. This was also a relatively common comment made when performance fell below the experienced pilot's high personal expectations. Overall, however, the written comments were quite positive with respect to "sharpening basic skills," responding to emergency situations, and providing recurrent training.

The second set of questions referred to specific aspects of flights that might or might not benefit from simulator training. All questions received positive ratings with the exception of $2 c$, which concerned the usefulness of this type of simulator for VFR recurrent training. Further, mean values of all questions other than $2 c$ were significantly above 5, except in the case of the 5.94 value for question $2 a$, which addressed the simulator's usefulness for basic flight control for student pilots in VFR and IFR conditions.

Although there was no significant overall difference for the third set of questions, the lowest mean score was that for question $3 \mathrm{~b}$, which concerned the importance of the simulator's visuals for its overall effectiveness. A low rating for this question was not unexpected since the visuals were used only during take-off and after breaking out for landing. The relatively low evaluation of the simulator's visual capability for these flights does not necessarily indicate that visuals were believed to be of little value for general simulator training, however, since the mean rating given to question $3 d$ regarding the general use of visuals in instrument flight training was higher at 6.29. This probably reflects an appreciation of the potential value of an interactive visual system for presenting a variety of situations to students practicing approaches. For this DOI: https://doi.org/10.15394/jaaer.1990.1024 

question the highest subgroup mean score was for those with a CFI rating.

Over half the participants rated the benefit of simulator visuals for instrument flight training at 7 or above.

It was expected that the full mission procedure would be given a high rating. Thus the 6.50 value obtained for question $3 \mathrm{c}$ was considered to be somewhat low, at least as compared to the higher overall usefulness ratings given to the questions of Set 1 and the question in Set 2 concerning the usefulness of practicing responses to problem situations. While not judged "not useful," the complete mission aspect of the flights clearly did not generate as much enthusiasm as their general use in training and flight proficiency, and especially in practicing responses to problem situations. There are several possible reasons for this. First, the problems of the flights were stressed in this study, with the LOFT playing more of a "set-up" or background role. Thus the in-flight problems became the focus of the participant's attention. Different and longer LOFT type scenarios that stressed flight planning to a greater degree might have been judged more valuable with respect to their complete mission aspect. Second, CFIs and other pilots such as those participating in the study may conceptualize instrument training primarily in terms of proficiency on individual instrument flight tasks and the learning of correct procedures to respond to specific emergency situations. To the extent that anticipated checkride problems are largely seen as involving such matters, it is expected that they will receive the greatest training emphasis.

Procedure trainers and simulators such as the Frasca 141 used in this study can be used to provide pilots of greatly different skill levels with a wide variety of training experiences. It is not difficult to prepare general ATC communications scenarios so that realistic full mission flights can be used in training. Such flights can include a variety of problems appropriate to the skill level of the pilot, the solutions to which should add greatly to the pilot's competence. The positive evaluation of this group of largely professional pilots suggests that relatively low-cost procedures trainers and simulators have a great deal to offer flight training beyond their common uses as trainers for standard IFR procedures. 
Dr.Leonard E. Ross is Professor and former Chair of the Department of Psychology of the University of Wisconsin, Madison. He is an instrument rated pilot with research interests in the effects of alcohol on pilot and driver performance and the use of simulators in aviation and automotive research.

Paul W. Slotten is an Academic Staff Specialist at the University of Wisconsin-Madison who has participated in several projects on alcohol use and aviation safety. He is also a CFII and charter pilot.

Dr. Louise M. Yeazel is an Associate Researcher on projects on alcohol use and aviation safety and a lecturer in the Department of Curriculum and Instruction at the University of Wisconsin-Madison. She is an instrument rated pilot, an instrument ground instructor at Madison Area Technical College, and a member of the Wisconsin Aerospace Education Committee.

\section{REFERENCES}

Helmreich, R.L., Wilhelm, B.A., Gregorich, B.A., \& Chidester, M.A. (1990). Preliminary results from the evaluation of cockpit resource management training: Performance ratings of flight crews. Aviation, Space, and Environmental Medicine, 61, 576-579.

Lombardo, D.A. (1987). Development of line oriented flight training for general aviation simulation. Simulation News/etter, $\underline{3}(1)$, Frasca International. 